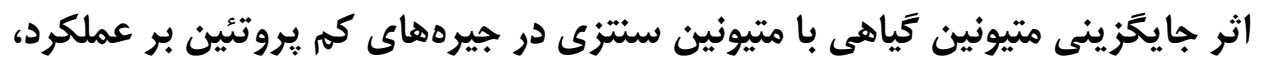

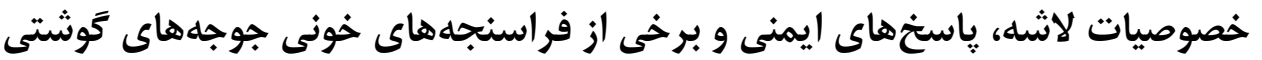

\author{
فرزاد محسن زاده تورى'، منصور رضائى 'و محمد كاظمى فرد؟ \\ ا و ז- دانش آموخته كارشناسى ارشد و استاديار، كروه علوم دامى، دانشكده علوم دامى و شيلات، دانشكاه علوم كشاورزى و منابع طبيعى سارى

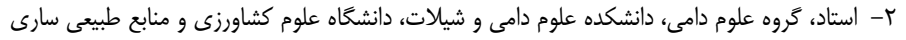

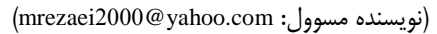 \\ ت
}

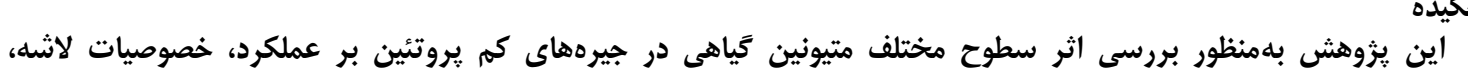

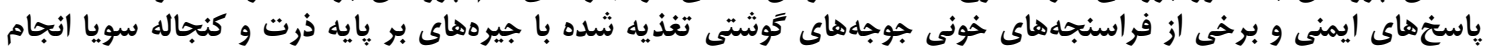

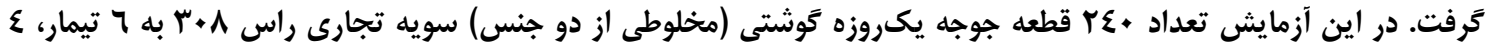

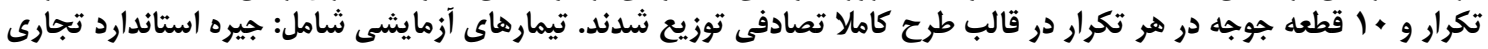

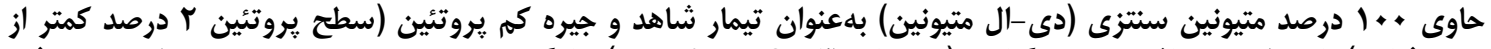

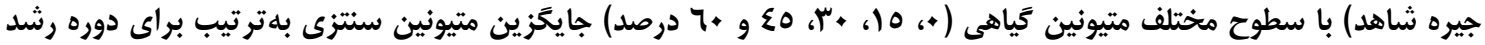

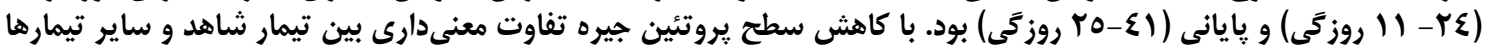

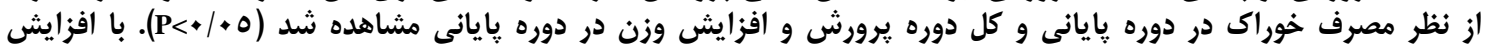

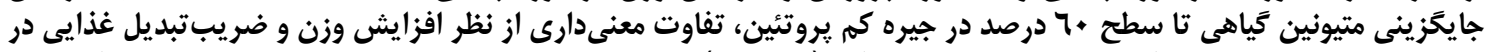

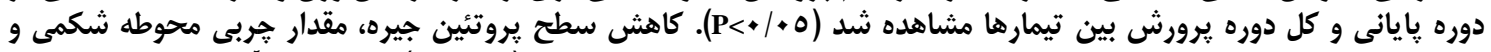
غلظت كلسترول، ترى

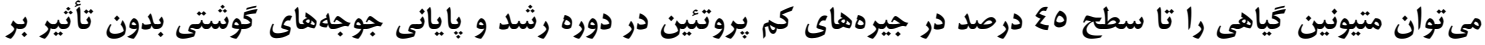

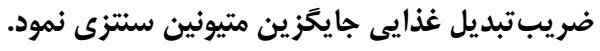

وازههاى كليدى: جوجه تَشتى، جيره كم يروتئين، متيونين تياهى، عملكرد

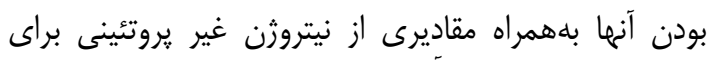

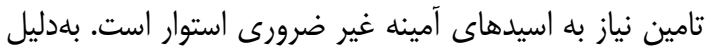

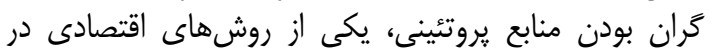

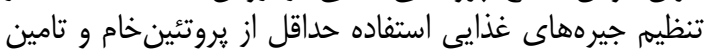

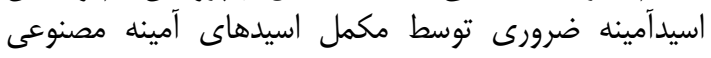

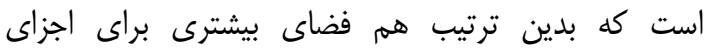

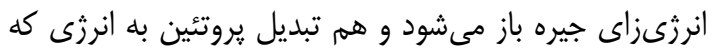

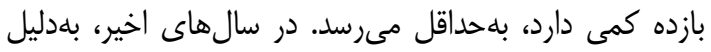

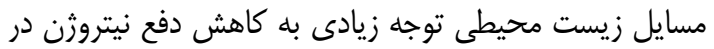

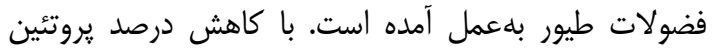

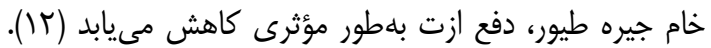

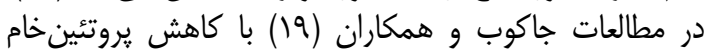

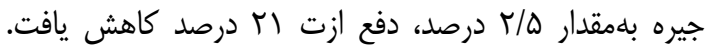

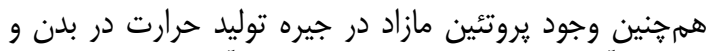

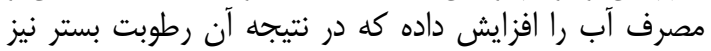

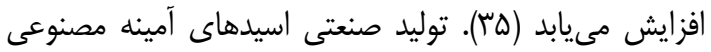

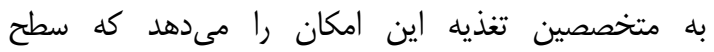

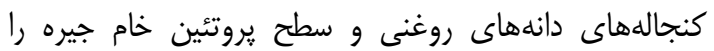

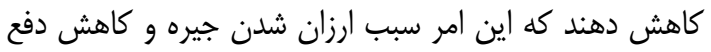

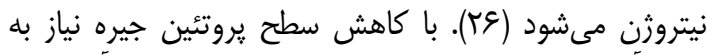

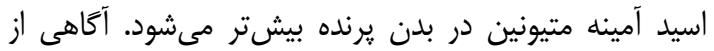

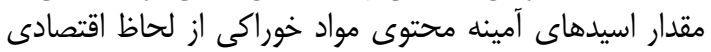

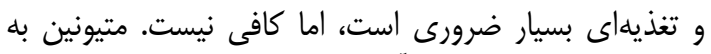

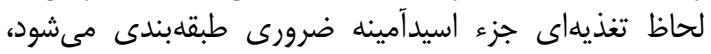

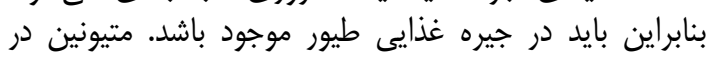

مقدمه

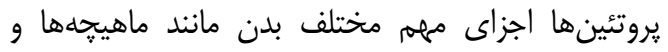

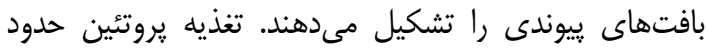

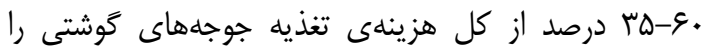

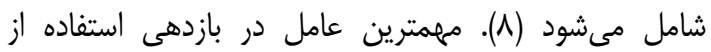

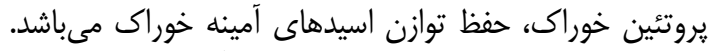

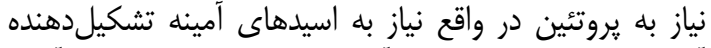
آن است. در بين اسيدهاى آمينه، متيونين نخستين اسين اسيدآمينه

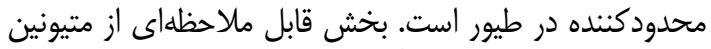

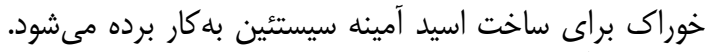

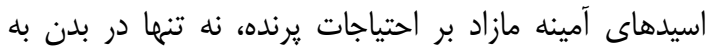

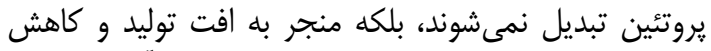

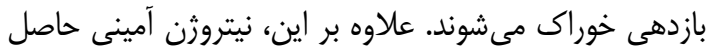

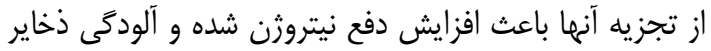

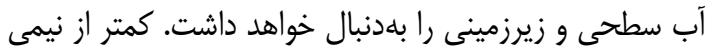

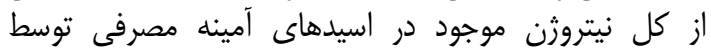

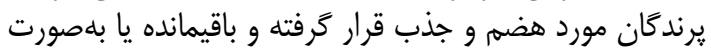

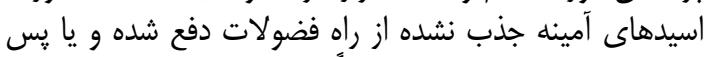

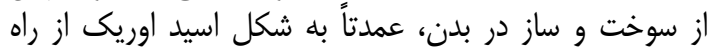

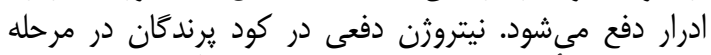

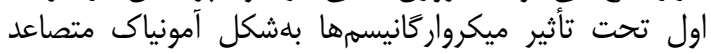

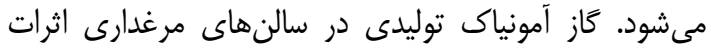

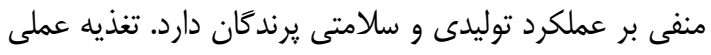

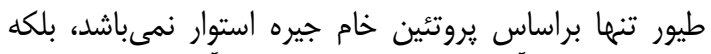
مقدار اسيدهاى آمينه ضرورى جيره، توازن آنها و قابئ استئ استفاده 
مىشود. مطالعات اخير نشان دادهاند كه استفاده از

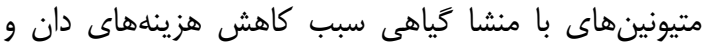

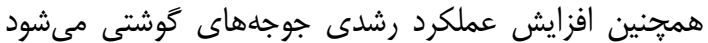

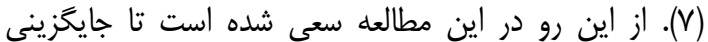

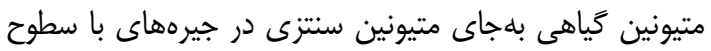

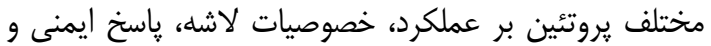

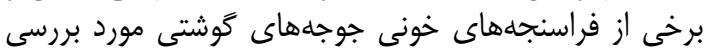

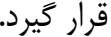

\section{مواد و روشها}

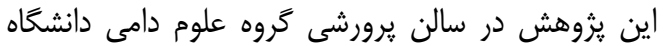

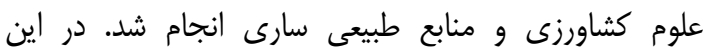

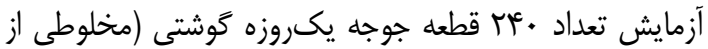

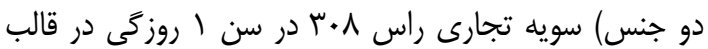

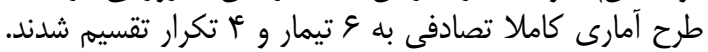

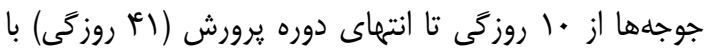

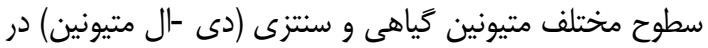

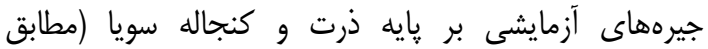

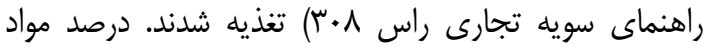

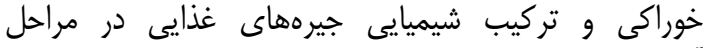

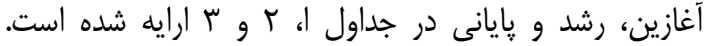

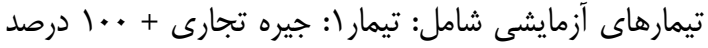

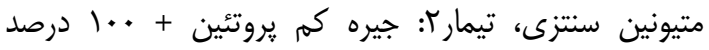

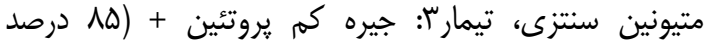

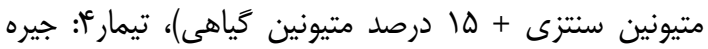

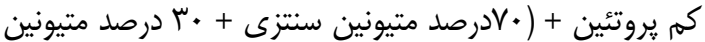

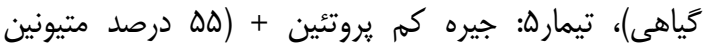

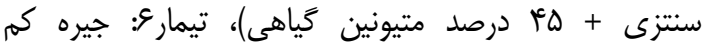

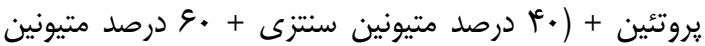

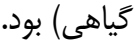

بيشتر از صد واكنش متيلاسيون كه شامل سنتز

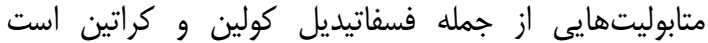

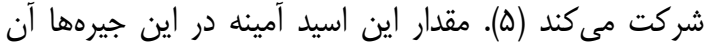

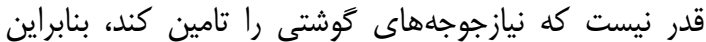

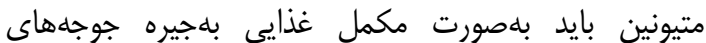

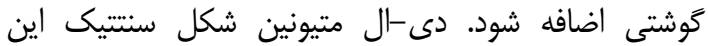
اسيدآمينه است كه در جيره طيور بيشتر مورد استفاده قرار

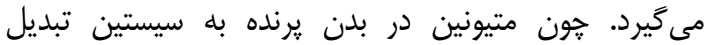

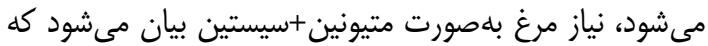

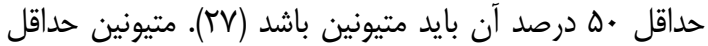

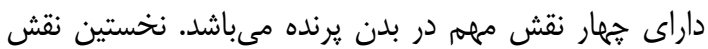

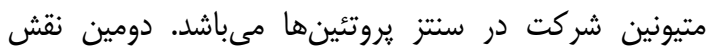

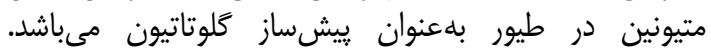

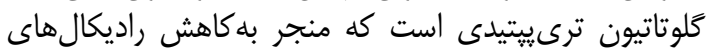

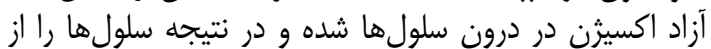

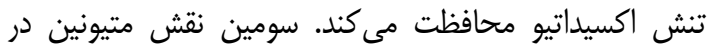

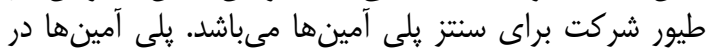

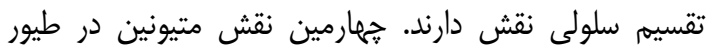

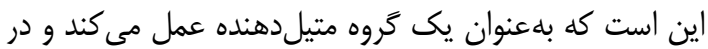

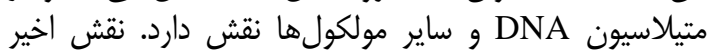

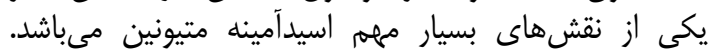

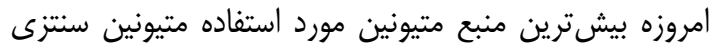

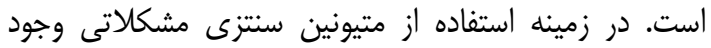

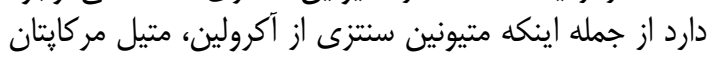

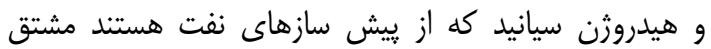

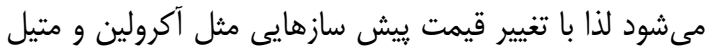

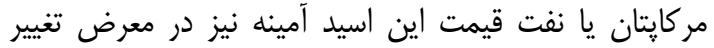

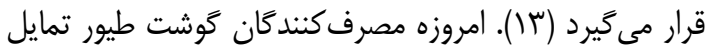
به مصرف محصولات با منشا كياهى دارند. در همين زين زمينان

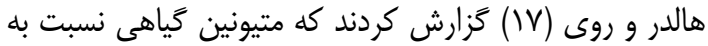

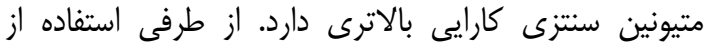

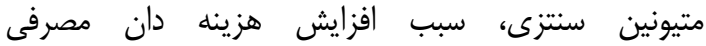


جدول ا- درصد مواد خوراكى و تر كيب شيميايى جيرههاى آزمايشى در دوره آغازين (•ا-1 روزگى) Table 1. Ingredients and chemical composition of experimental diets in starter period (1 to 10 days)

\begin{tabular}{|c|c|}
\hline درصد ماده خوراكى & ماده خوراكى \\
\hline$\Delta F / T Y$ & ذرت \\
\hline 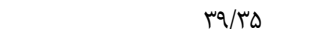 & كنجاله سويا \\
\hline $1 / 99$ & روغن سويا \\
\hline $1 / 99$ & دى كلسيم فسفات \\
\hline $1 / 19$ & سنگ آهى \\
\hline 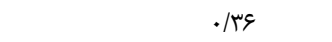 & نمك \\
\hline.$/ T \Delta$ & مكمل معدنى" \\
\hline$\cdot / T \Delta$ & "مكمل ويتامينه" \\
\hline$\cdot / \mu$ & دى - ال متيونين \\
\hline$\cdot / \mu 1$ & ال-ليزين هيدروكلرايد \\
\hline.$/ 11$ & ال-ترئونين \\
\hline $1 \ldots$ & جمع كل \\
\hline & تركيب شيميايى (\%) \\
\hline rq.. & انرزى قابل متابوليسم (كيلو كالرى / كيلو گرم) \\
\hline$r t / T$ & يروتئين \\
\hline . /9r & 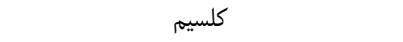 \\
\hline$\cdot / 48$ & فسفر قابل دسترس \\
\hline.$/ \mathrm{V}$ & سـيمَ \\
\hline $1 / 44$ & 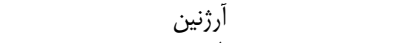 \\
\hline $1 / \% q$ & 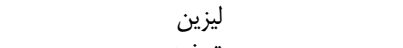 \\
\hline$\cdot / 94$ & متيونين \\
\hline $1 / \cdot 4$ & متيونين + سيستئين \\
\hline$\frac{}{. / 94}$ & 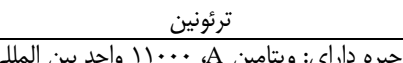 \\
\hline
\end{tabular}

جدول r- درصد مواد خوراكى و تر كيب شيميايى جيرههاى آزمايشى در دوره رشد (أب-Iا روزگى) Table 2. Ingredients and chemical composition of experimental diets in grower period (11 to 24 days)

\begin{tabular}{|c|c|c|c|c|c|c|}
\hline 9 & $\Delta$ & $i^{f}$ & $r$ & $r$ & 1 & ماده خوراكى (\%) \\
\hline GT/99 & $9 \% / 99$ & gr/99 & $95 / 99$ & $9 \pi / T^{2}$ & $\mathrm{DV} / \mathrm{WV}$ & ذرت \\
\hline$r \cdot / v a$ & $r \cdot / v \Delta$ & $r \cdot / v \Delta$ & $r \cdot / v a$ & r T/א. & ra/rs & كنجاله سويا \\
\hline $1 / 9 \mu$ & 1/94 & 1/94 & $1 / 9 \mu$ & I/AV & t/AT & روغن سويا \\
\hline $1 / \Delta F$ & V/DF & V/DF & $V / \Delta F$ & $V / \Delta F$ & $1 / 49$ & دى كلسيم فسفات \\
\hline $1 / \cdot 1$ & $1 / \cdot 1$ & $1 / \cdot 1$ & $1 / \cdot 1$ & $1 / \cdot 1$ & $1 / \cdot v$ & سنَ آهى \\
\hline •/rv & •/ $r$ & $\cdot / r v$ & •/ r & •/ $\mathrm{r} V$ & •/ $r$ & نمك \\
\hline.$/ T \Delta$ & $\cdot / r \Delta$ & •/Ta & $\cdot / T \Delta$ & $\cdot / r \Delta$ & $\cdot / \pi \Delta$ & مكمل معدنى" \\
\hline ./TA & . /TA & . /TD & - /TA & •/ra & . /TA & مكمل ويتامينه" \\
\hline 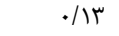 & $\cdot / 1 \Lambda$ & שr/ & $\cdot / 4 \Lambda$ & 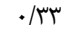 & 落 & دى -|ال متيونين \\
\hline.$/ r$. & .110 &.$/$. & .1 .0 &.$/$. &.$/$. & متيونين گياهى \\
\hline$\cdot / 4$ & $\cdot / 4$ & $\cdot / 4$ & $\cdot / 4$ & $\cdot / 4$ & $\cdot / \pi r$ & ال-ليزين هيدروكلرايد \\
\hline.$/ 19$ &.$/ 19$ &.$/ 19$ &.$/ 19$ & $\cdot / 9$ & .1 .9 & ال-ترئونين \\
\hline \multirow[t]{2}{*}{$1 \ldots$} & $1 .$. & $1 .$. & $1 \ldots$ & $1 .$. & $1 .$. & جمع كل \\
\hline & & & & & & تركيب شيميايى (\%) \\
\hline$r \ldots$ & $r \ldots$ & $r \ldots$ & $r \ldots$ & $r \ldots$ & $r \ldots$ & 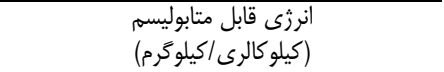 \\
\hline $\mathrm{N} / \mathrm{V}$. & $\mathrm{N} / \mathrm{V}$. & $W / v$. & $W / v$. & $\mathrm{W} / \mathrm{V}$. & $r \cdot / \mathrm{V}$. & يروتئين خام \\
\hline - /AF & - /Ar & - /AF & - /Ar & - /Af & $\cdot / \Lambda t$ & كلسيم \\
\hline . & . & T & . AT & . & Th & فسفر قابل دسترس \\
\hline.$/ \mathrm{V}$ &.$/ \mathrm{V}$ &.$/ \mathrm{V}$ & $\cdot / \mathrm{V}$ & $\cdot / \mathrm{V}$ & $\cdot / \mathrm{V}$ & سديم \\
\hline$\cdot / \Lambda$ & $\cdot / 1$ & $\cdot / \Lambda$ & $\cdot / 1$ & $\cdot / 1$ & $\cdot / 1$ & 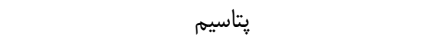 \\
\hline$r \cdot r$ & r.r & $r \cdot r$ & $r \cdot r$ & $r \cdot r$ & MTE & تعادل الكتروليتى جيره (ميلى اكى والان /كيلوكَرم) \\
\hline I/r & $1 / r r$ & $1 / r r$ & I/r & $1 / \mu r$ & $1 / \% r$ & آرثزنين \\
\hline $1 / T^{2}$ & $1 / \pi+$ & $1 / r e$ & $1 / \mu^{E}$ & $1 / \mu^{e}$ & $1 / \pi e^{e}$ & ليزين \\
\hline$\cdot / \Delta V$ & $\cdot / \Delta V$ & $\cdot / \Delta V$ & $\cdot / \Delta V$ & $\cdot / \Delta \mathrm{V}$ & $\cdot / \Delta V$ & متيونين \\
\hline.$/ 90$ & $\cdot / 9 \Delta$ & $\cdot / 90$ &.$/ 90$ & $\cdot / 9 \Delta$ &.$/ 9 \Delta$ & متيونين + سيستئين \\
\hline •/AD & •/AD & - $/ \Lambda \Delta$ & $\cdot / \Lambda \Delta$ & •/^৯ & •/A $\Delta$ & ترئونين \\
\hline
\end{tabular}




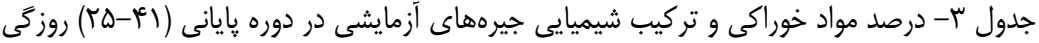
Table 3. Ingredients and chemical composition of experimental diets in finisher period (25 to 41 days)

\begin{tabular}{|c|c|c|c|c|c|c|}
\hline 9 & $\Delta$ & $f$ & $r$ & $r$ & 1 & ماده خوراكى (\%) \\
\hline$V \cdot / \Delta)^{c}$ & $V \cdot / \Delta T^{C}$ & $V \cdot \mid \Delta T^{C}$ & $V \cdot / \Delta F$ & $V \cdot / \Delta F$ & $9 Y / 99$ & ذرت \\
\hline rT/r. & $r \pi / r$. & $r / r$. & r & . & $r \cdot / r$. & كنجاله سويا \\
\hline$r / 1$. & $r / l$. & $r / 1$. & $r / l$. & $r / l$. & 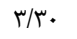 & روغن سويا \\
\hline $1 / \infty$ & $1 / \infty$ & $1 / \Delta$ & $1 / \Delta$ & $1 / \Delta$. & $1 / \mu$. & دى كلسيم فسفات \\
\hline$\cdot / \Lambda \Delta$ & $\cdot / \Lambda \Delta$ & $\cdot / \wedge \Delta$ & $\cdot / \Lambda \Delta$ & $\cdot / \Lambda \Delta$ &.$/ 91$ & سنگ آهك \\
\hline$\cdot / 4$ & $\cdot / 4$ & $\cdot / 4$ & $\cdot / 4$. & $\cdot / 4$. &.$/ 19$ & نمك \\
\hline$\cdot / T \Delta$ & $\cdot / r \Delta$ &.$/ T \Delta$ &.$/ T \Delta$ &.$/ T \Delta$ &.$/ T \Delta$ & مكمل معدنى" \\
\hline$\cdot / T \Delta$ & $\cdot / T \Delta$ &.$/ T \Delta$ & $\cdot / T \Delta$ & $\cdot / T \Delta$ &.$/ T \Delta$ & مكمل ويتامينه" \\
\hline.$/ 11$ &.$/ 19$ & $\cdot|/|$ & (T/ & $\cdot|r|$ & $\cdot / T \Delta$ & دى-ال متيونين \\
\hline$\cdot / 4$. &.$/ 10$ &.$/ 1$ & $.1 \cdot \Delta$ &.$/$ & .1. & متيونين گياهى \\
\hline$\cdot / \kappa$ & $\cdot / \kappa$ & $\cdot / 4$ & $\cdot / 4$. & $\cdot / r v$ & 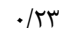 & ال-ليزين هيدروكلرايد \\
\hline.$/ 14$ &.$/ 14$ &.$/ 14$ &.$/ 14$ &.$/ 14$ & .1 .9 & ال-ترئونين \\
\hline$\cdot / \% \Delta$ & • & 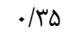 & 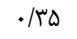 & $\cdot /$ L & 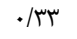 & بى كربنات سديم \\
\hline \multirow[t]{2}{*}{$1 \ldots$} & $1 \ldots$ & $1 \ldots$ & $1 \ldots$ & $1 \ldots$ & $1 \ldots$ & جمع كل \\
\hline & & & & & & تركيب شيميايى (\%) \\
\hline आ... & 1.. & ऍ... & 以... & 1... & r... & 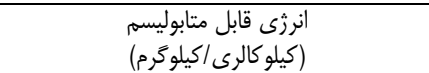 \\
\hline $18 / 19$ & $18 / 19$ & $18 / 19$ & $18 / 19$ & $19 / 19$ & $11 / 19$ & يروتئين خام \\
\hline$\cdot / V \Delta$ & $\cdot / V \Delta$ & $\cdot / V \Delta$ & $\cdot / V \Delta$ & $\cdot / V \Delta$ & $\cdot / V \Delta$ & كلسيه \\
\hline$\cdot / T V$ & $\cdot / r v$ & $\cdot / r v$ & $\cdot / r v$ & $\cdot / r v$ & $\cdot / r v$ & فسفر قابل دسترس \\
\hline.$/ 1 V$ & $\cdot / I V$ &.$/ \mathrm{VV}$ &.$/ I V$ &.$/ N V$ &.$/ N V$ & سديم \\
\hline$\cdot / \mathrm{V} \Lambda$ & $\cdot / \mathrm{VA}$ & $\cdot / \mathrm{VA}$ & $\cdot / \mathrm{V} \wedge$ & $\cdot / \mathrm{r} \wedge$ & $\cdot / \wedge \mathrm{V}$ & يتاسيم \\
\hline$r \cdot$. & $r .$. & r.. & $r .$. & $r .$. & THI & تعادل الكتروليتى جيره (ميلى اكى والان /كيلوگرم) \\
\hline $1 / \mu$. & $1 / \mu$. & $1 / \mu$. & $1 / \pi$. & $1 / \mu$. & $1 / \mu$. & آررزنين \\
\hline $1 / 11$ & $1 / 11$ & $1 / 11$ & $1 / 11$ & $1 / 11$ & $1 / 11$ & ليزين \\
\hline$\cdot / 0$ & $\cdot / 0$ & $\cdot / \Delta \cdot$ & .10 & .10 &.$/ 0$ & متيونين \\
\hline$\cdot / \Lambda \mathrm{V}$ & -/AV & ./AV & ./AV & ./AV & -/AV & متيونين + سيستئين \\
\hline$\cdot / V \Delta$ & $\cdot / V \Delta$ & $\cdot / V \Delta$ & $\cdot / V \Delta$ & $\cdot / V \Delta$ & $\cdot / V \Delta$ & 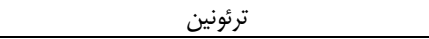 \\
\hline
\end{tabular}

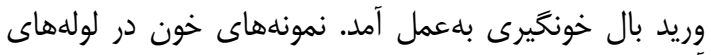

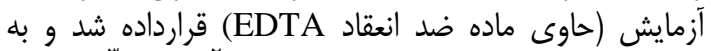

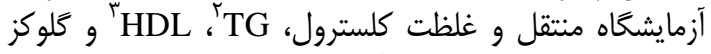

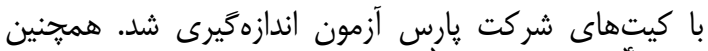

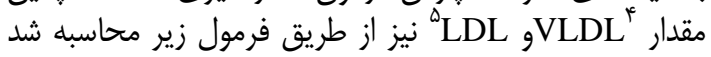

$\mathrm{LDL}=$ TotalCholesterol (T.C) $-\mathrm{VLDL}=\frac{\mathrm{TG}}{5}$ (HDL+VLDL)

براى ارزيابى پاسخ ايمنى جوجههاى مورد آزمايش،

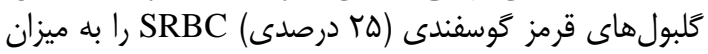

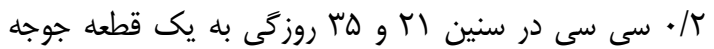

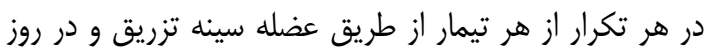

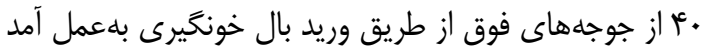

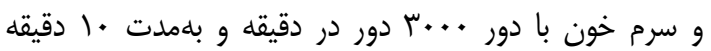

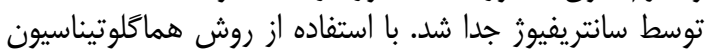

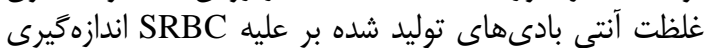

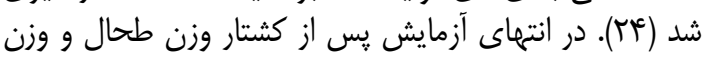

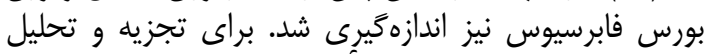

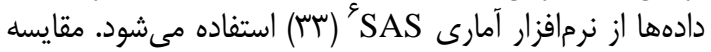

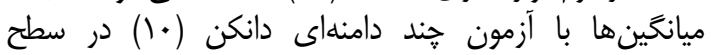
معنى دار ه • • • انجام مى شود. أنمون جند
متيونين كياهى توليد شركت Arosol كشور هند مىباشد

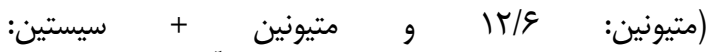

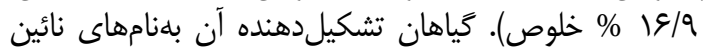

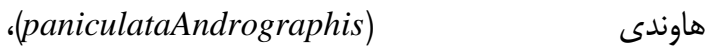

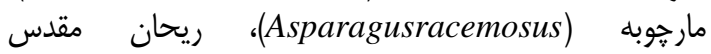
(Silybium marianum) و خارمريم (Ocimum sanctum)

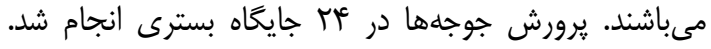

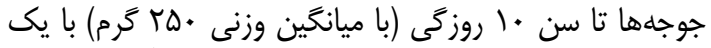

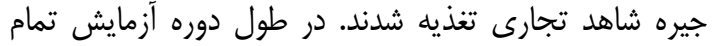

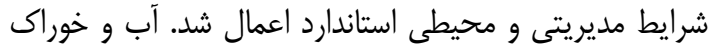

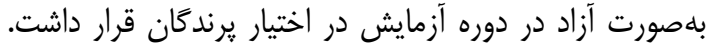

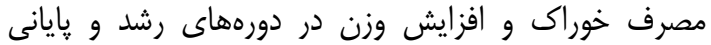

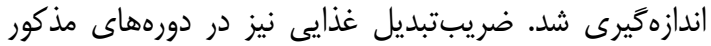

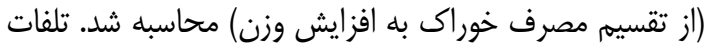

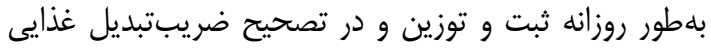

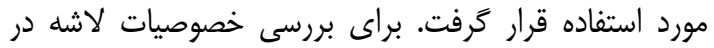

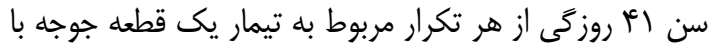

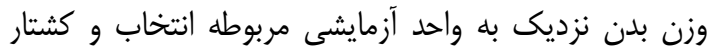

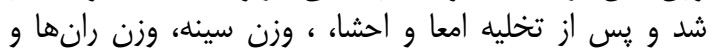

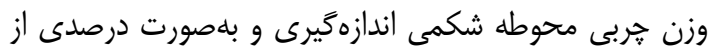

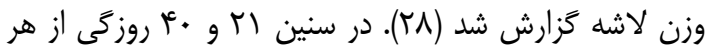

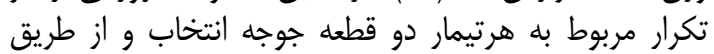

1- Methorganic (Herbal Methionine)

2- Triglyceride

5- Low Density Lipoprotein

3-High Density Lipoprotein 6- Statistics Analysis System 
تا سطح •و درصد باعث كاهش وزن و افزايش ضريبتبديل

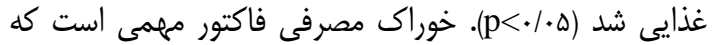

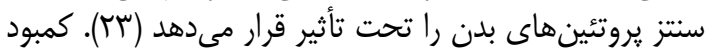

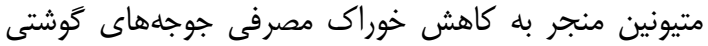

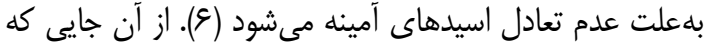

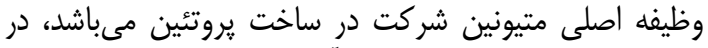

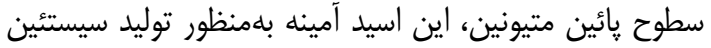

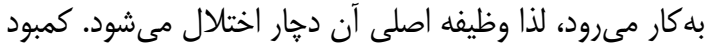

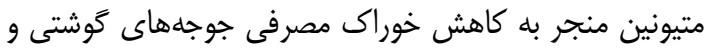

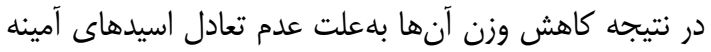

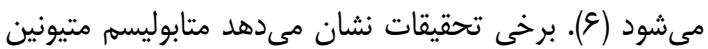

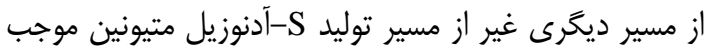

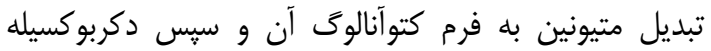

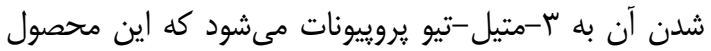

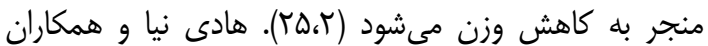

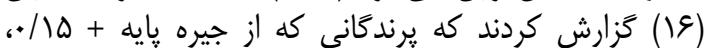

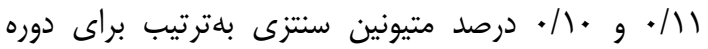

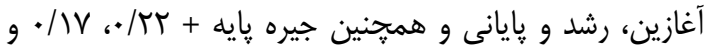

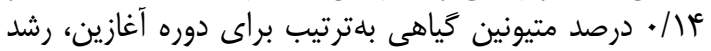

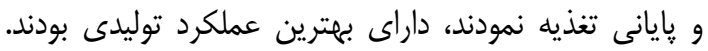

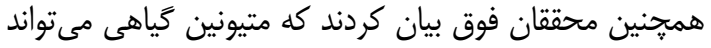

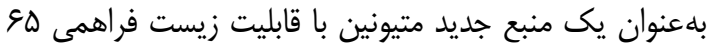

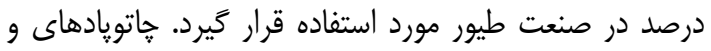

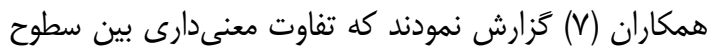

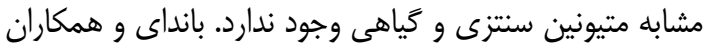

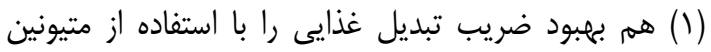

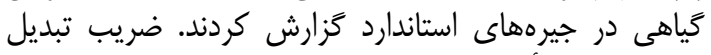

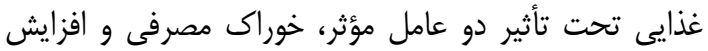

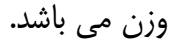

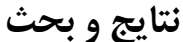

طبق جدول (أ) با كاهش سطح بروتئين، مصرف خوراك

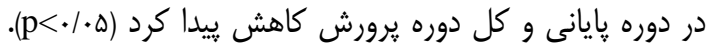

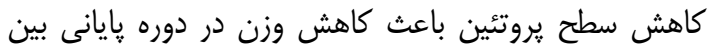

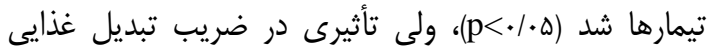
نداشت. كاهش سطح يروتئين در جيره حاوى متيونين الثين سنتزى

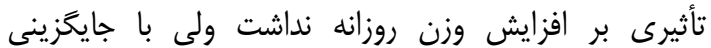

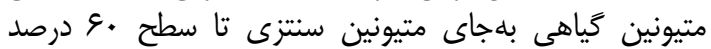

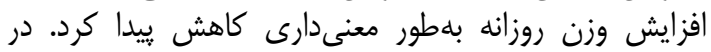

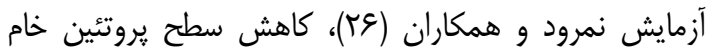

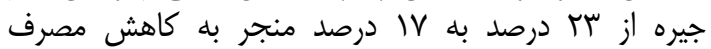
خوراك شد. اين محققين تئورى آمينواستاتيك را برائ براى توجيه

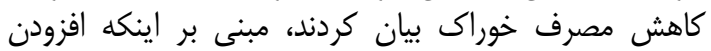

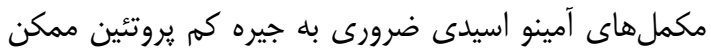

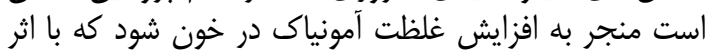

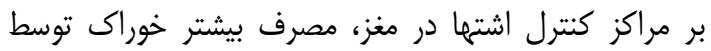

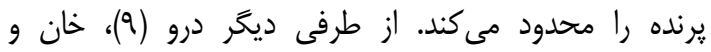

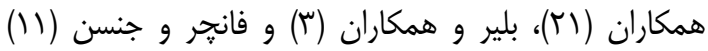

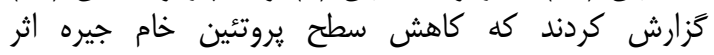

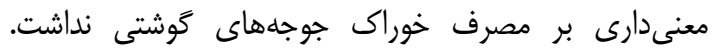

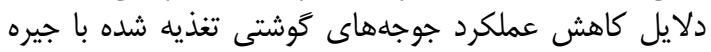

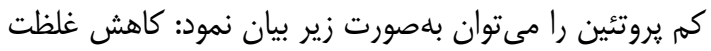

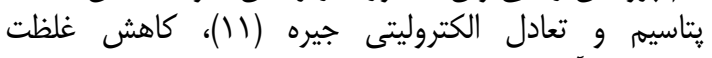

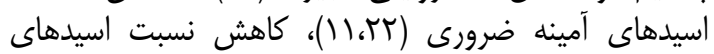

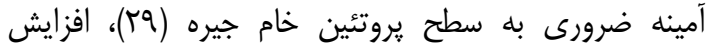

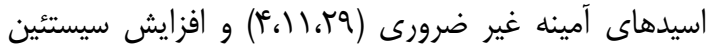

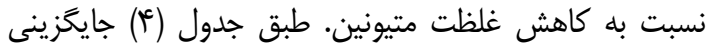

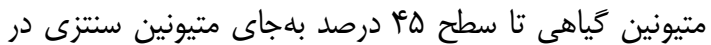

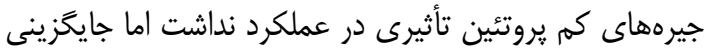

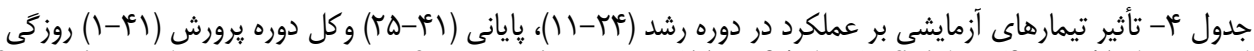
Table 4. Effect of experimental treatments on performance in grower (11 to 24 days), finisher (25 to 41 days) and

\begin{tabular}{|c|c|c|c|c|c|c|c|c|c|}
\hline \multicolumn{3}{|c|}{ 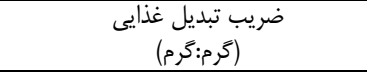 } & \multicolumn{3}{|c|}{ (كرم/ايشنده/رزن) } & \multicolumn{3}{|c|}{ 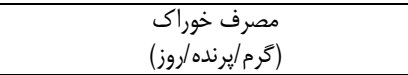 } & \multirow[b]{2}{*}{ تيمارها } \\
\hline كل دوره & קֶايانى & رشد & كل دوره & קֶايانى & رشد & كل دوره & קֶايانى & رشد & \\
\hline $1 / 99^{\circ}$ & $1 / V \Lambda^{\circ}$ & $T / \Delta F^{c}$ & $V Q / \kappa F^{a}$ & $\Lambda \varepsilon / \Lambda \cdot{ }^{a}$ & $91 / 94$ & $1 T V / q V^{a}$ & $1 \omega F / \Lambda \mu^{d a}$ & $9 \Delta /{ }^{\prime} \bar{q}$ & 1 \\
\hline $1 / 99^{\circ}$ & $1 / v 9^{0}$ & $1 / \Delta \Delta$ & $v e / 1$. ao & $\Lambda \Gamma /\left.F\right|^{D}$ & $9 r / V q$ & $\mid r \Delta / \Delta \gamma^{D}$ & $\mid \kappa q / \wedge r^{D}$ & QV/Aน & r \\
\hline $1 / 99^{\circ}$ & $1 / \mathrm{v}^{\mathrm{D}}$ & $1 / \Delta \Delta$ & $V r / \Delta 1^{D}$ & $\wedge \mu / \cdot q^{D}$ & SI/AV & $|K F / q|^{D}$ & D & $Q \varepsilon / \mathcal{T V}$ & $\mu$ \\
\hline $1 / N^{D}$ & $1 / \mathrm{vq}^{\mathrm{D}}$ & $1 / \Delta F^{c}$ & $v r / 19^{D}$ & $\Lambda r / \Lambda)^{D}$ & $9 / / D 1$ & $\mid r \Delta / \Delta T^{D}$ & $\mid f \wedge / \Lambda \varepsilon^{D}$ & $9 \Delta / \Gamma \varepsilon$ & f \\
\hline $1 / N^{D}$ & $1 / \mathrm{v}^{\mathrm{D}}$ & $1 / \Delta q$ & $V r / r I^{D}$ & 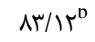 & $91 / 11$ & $\mid r \Delta / \Delta \mathcal{F}^{\mathrm{D}}$ & $\| f \wedge / V^{D}$ & Q & $\Delta$ \\
\hline $1 / v \Lambda^{a}$ & $1 / 9 r^{\mathrm{a}}$ & $1 / \Delta \Lambda$ & $99 / 9 V^{c}$ & $V g / q Y^{c}$ & $S I / \Delta T$ & $\mid r F / 9 Y^{D}$ & $1 f V / V \cdot 0^{D}$ & $q \vee / T q$ & 9 \\
\hline.$/ .1$ &..$\cdot r$ &.$/ \cdot 1$ & . kat & $\cdot|\Lambda|$ & $\cdot / 4 F$ & TET & . IV & - /AF & SEM \\
\hline.$/ . \cdot 1$ &.$/ \ldots q$ & .119 &.$|\cdots|$ &.$|\cdots|$ &.$/ 48$ & $. / .1 . r$ &.$/ . .1$ &.$/ \% \Delta$ & $P$ value \\
\hline
\end{tabular}

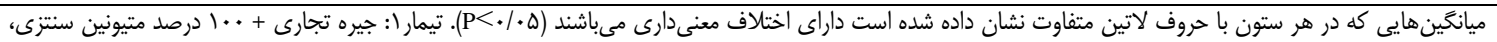

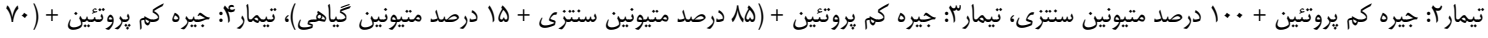

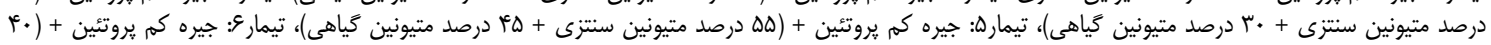
درصد متيونين سنتزى + •9 درصد متيونين كياهى).

تربى محوطه شكمى را بهطور معنىدار افزايش داد، اما تأثير

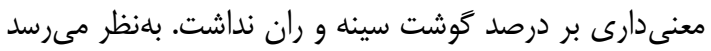

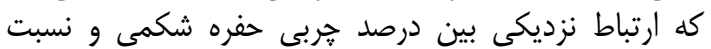

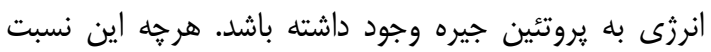

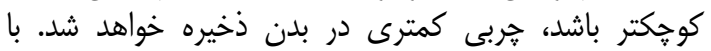

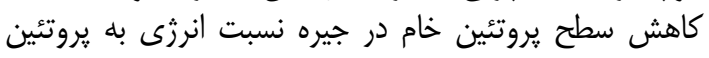

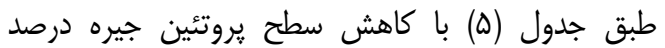

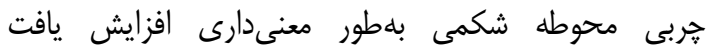

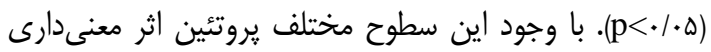

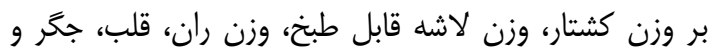

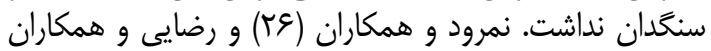
(آ) كزارش كردند كاهش سطح يروتئين خام جيره درصد 


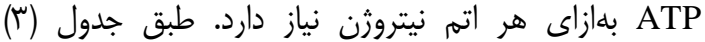

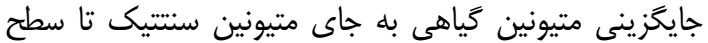

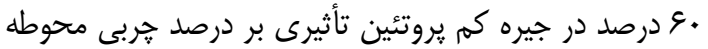

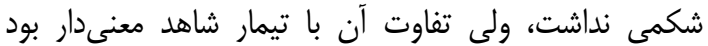

.$(\mathrm{p}<\cdot / \cdot \omega)$
تغيير يافته و مقدار بيشترى انرزى در دسترس بوده، بنابراين

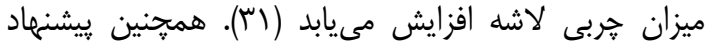

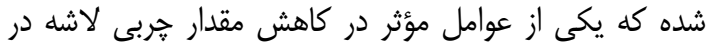

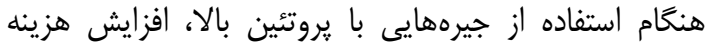

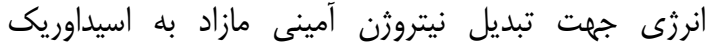
مىباشد. دفع نيتروثن مازاد به صورت اسيد اوريك به به 9 مول أرين

جدول ه- تأثير تيمارهاى آزمايشى بر خصوصيات لاشه" (\%)

Table 5. Effect of experimental treatments on carcass characteristics (\%)

\begin{tabular}{|c|c|c|c|c|c|c|c|c|c|}
\hline بورس فابريسيوس & طحال & سنحَدان & هربى شكمى & قلب & كبد & سينه & ران & لاشه خالص & تيمارها \\
\hline$\cdot / 1 \wedge$ & $\cdot / \mathrm{IV}$ & $1 / 94^{2}$ & $r / a r^{b}$ &.$/ 8$. & $\mathrm{r} / \mathrm{M}$ & TI/TH & $r N / K^{*}$. & SV/TM & 1 \\
\hline.$/ 14$ & $\cdot / \mathrm{VV}$ & $1 / \Lambda$. & $r / \mu \cdot a$ & $\cdot|8|$ & $r / \Lambda$. & rq/19 & rV/Aq & SV/AF & r \\
\hline r & $\cdot / 11$ & $1 / 94$ & $r / \mu I^{a}$ & $\cdot / \Delta \phi$ & $r / \Phi_{0}$ & rq/q1 & $r q / \Delta r$ & SV/TH & r \\
\hline (1/ & $\cdot / 1 \Lambda$ & $1 / V \pi$ & $\mu / \mu \omega^{a}$ & $\cdot \mid \Delta \varphi$ & $r / \Lambda)$ & $r \cdot / \Delta T$ & rN/QT & GD/AT & $\Delta$ \\
\hline.$/ 14$ & $\cdot / \mathrm{VV}$ & $1 / v 9$ & $r / \Delta \cdot a$ & $\cdot / \Delta \Lambda$ & $r / \Delta$. & $r q / 10$ & $r q / q g$ & $S \mathrm{~V} / \cdot \Delta$ & 9 \\
\hline
\end{tabular}

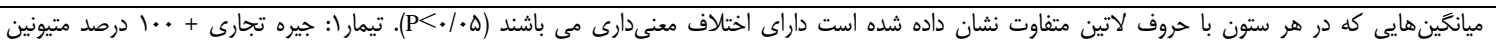

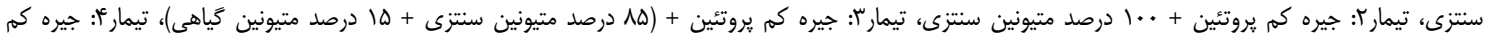

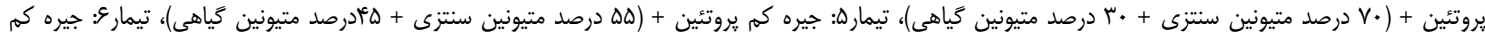

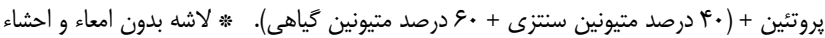

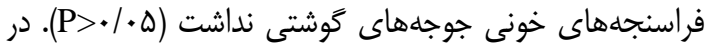

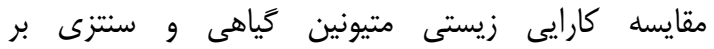

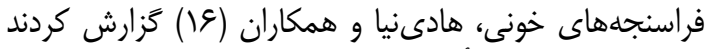

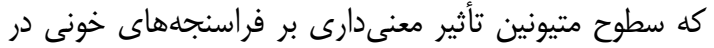

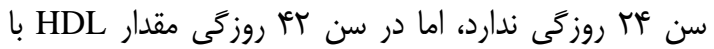

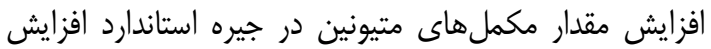

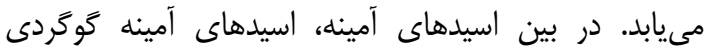

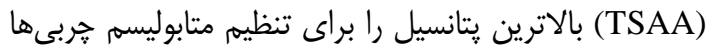

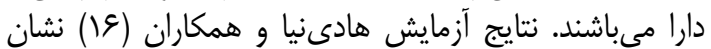

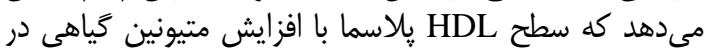
جيره افزايش معنى دارى نشان داد.
طبق جدول (ع) كاهش سطح يروتئين جيره باعث افزايش

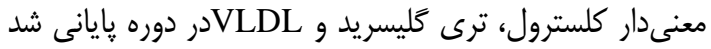

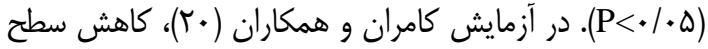

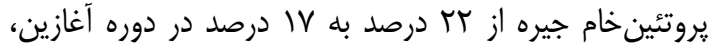

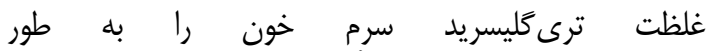

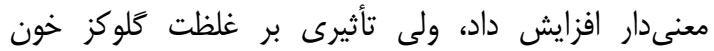
نداشت. غياثى و همكاران (10) نشان دادئ دادند كه كاهش

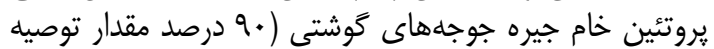

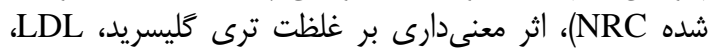

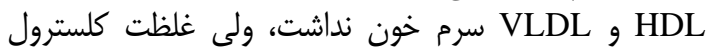

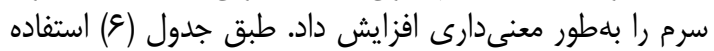

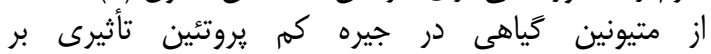

جدول צ- تأثير تيمارهاى آزمايشى بر غلظت فراسنجهاى خونى در سن آ و أ روزگى (ميلى گرم/دسى ليتر) Table 6. Effect of experimental treatments on blood parameters at 21 and 41 days of age (mg/dl)

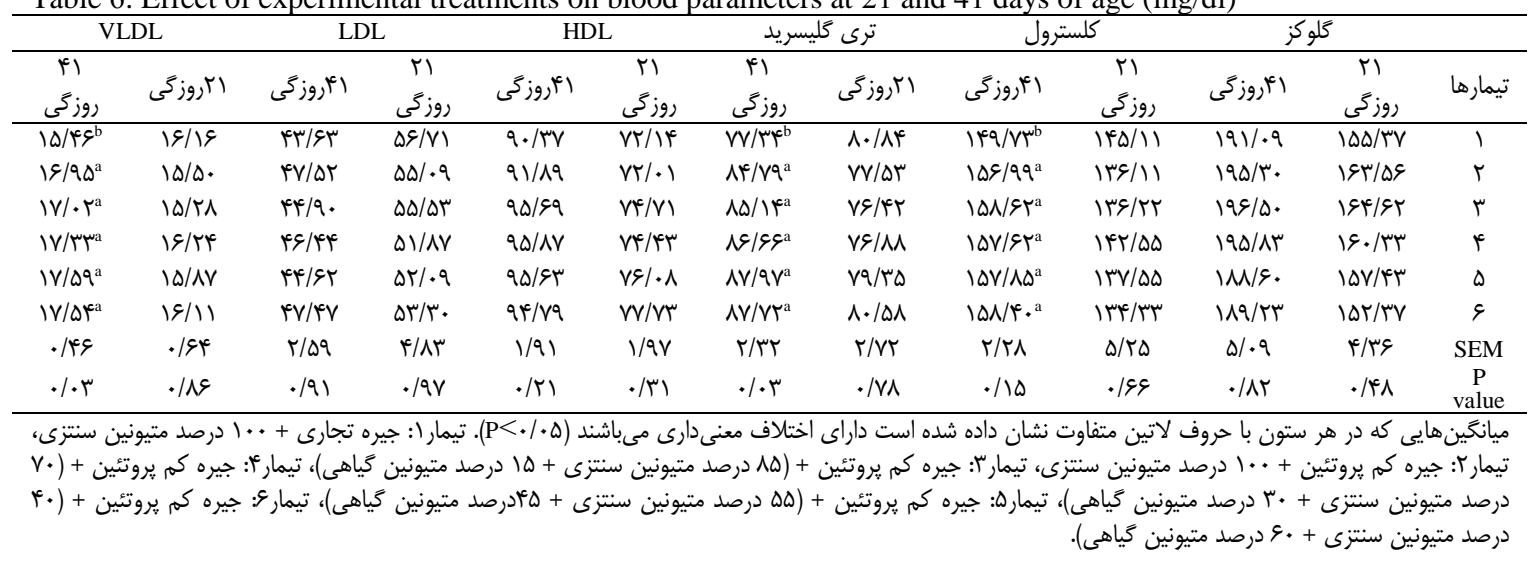

معنى دارى بر تعداد كلبول سفيد، لنفوسيت، مونوسيت و ائوزينوفيل نداشت كه اين كزارش با نتايج بدست آمارد

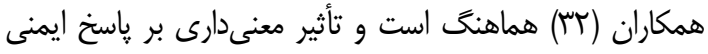

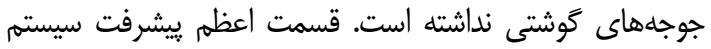

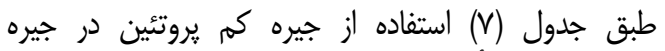

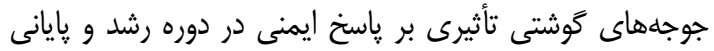

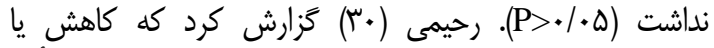

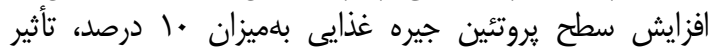




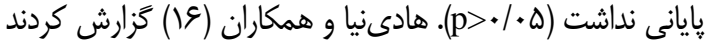

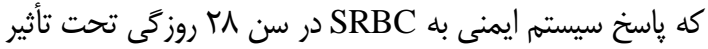

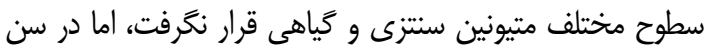

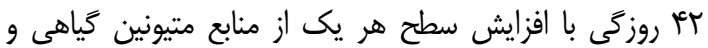

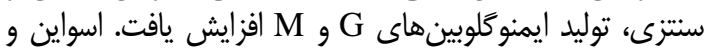

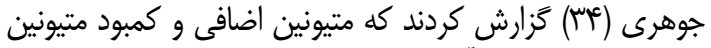

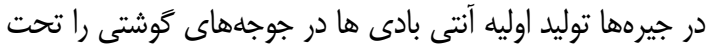

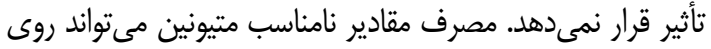

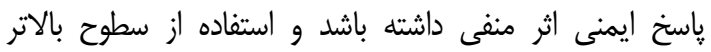

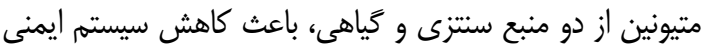

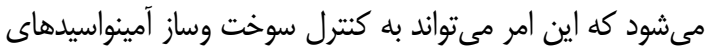
كوَّرد دار و تغييرات متابوليكى در هاسخ به به تغييرات در مر متيونين

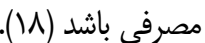

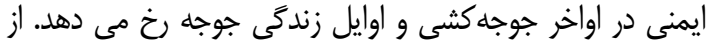

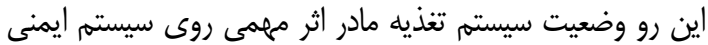

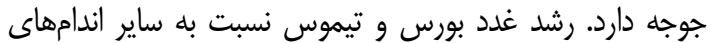

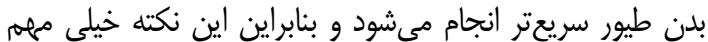

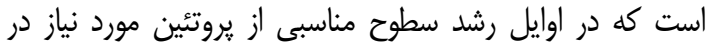

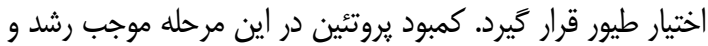

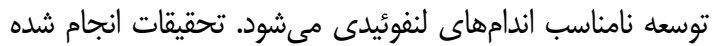

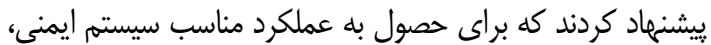

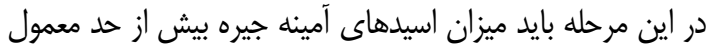

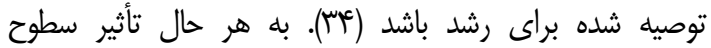

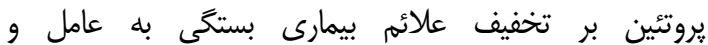

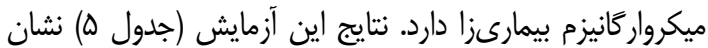

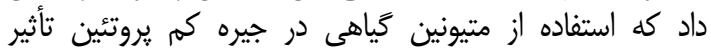

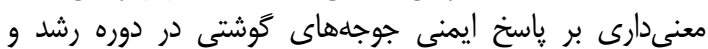

Table 7. Effect of experimental treatments of humoral immune response (log

جدول V- تأثير تيمارهاى آزمايشى بر ياسخ ايمنى همورال (برحسب

\begin{tabular}{|c|c|c|c|c|c|c|}
\hline \multicolumn{2}{|c|}{ IgM } & \multicolumn{2}{|c|}{$\mathrm{IgG}$} & \multicolumn{2}{|c|}{ تيتركل } & \multirow[b]{2}{*}{ تيمارها } \\
\hline • أروزى & ه广 روزى & + & هזروزگى & • • روزگى & ه广روزى & \\
\hline$r / T \Delta$ & $\Gamma / \Delta$. & $r / . \cdot$ & $r / V \Delta$ & $r / r \Delta$ & $\Delta / T \Delta$ & 1 \\
\hline$r / \Delta$. & $r / V Q$ & $r / .$. & $\Gamma / \Delta$. & $\kappa / \Delta$. & s/ra & $r$ \\
\hline $1 / v \Delta$ & $r / .$. & $1 / \pi \omega$ & $r / .$. & $r /$. & $81 .$. & r \\
\hline $1 / \pi \Delta$ & $r / T \Delta$ & $1 / .$. & $1 / T \Delta$ & $T / r \Delta$ & $\Gamma / \Delta$. & r \\
\hline$r / .$. & $T / T \Delta$ & $1 / r \Delta$ & $1 / v \Delta$ & $\Gamma / \tau \Delta$ & $r / .$. & $\Delta$ \\
\hline$T / T \Delta$ & $r / .$. & $1 /$. & $r / .$. & $\Gamma / \Gamma \Delta$ & $r / .$. & 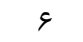 \\
\hline . $/ \Delta T$ & س & $\cdot / Q T$ & سו/1 & $\cdot / V^{c}$ & $1 / \pi \Delta$ & SEM \\
\hline.$|8|$ &.$/ 9 \Delta$ & $.1 \Delta S$ &.$|Q|$ & זr/. & . $/ \Delta T$ & $\mathrm{P}$ value \\
\hline
\end{tabular}

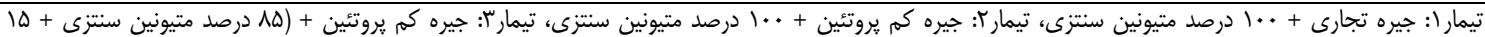

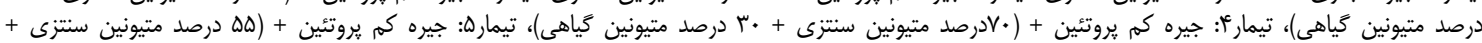

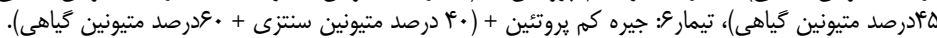

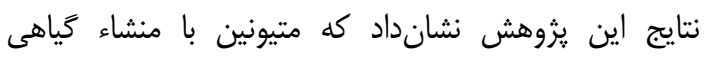

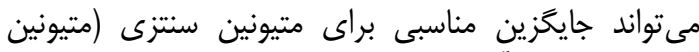

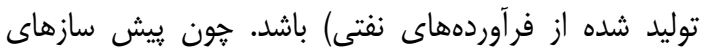

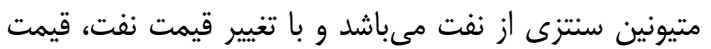

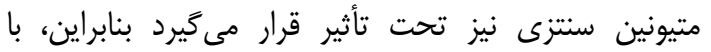

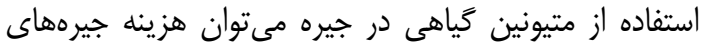

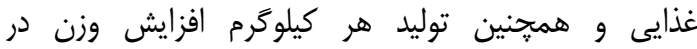
جوجهاى گَشتى را كاهش داد.

تشكر و قدردانى نويسندكان از شركت كَلبار شيمى داني دانه بهخاطر فراهم

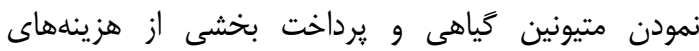
آزمايش سياسگَزارى مى كنتد.
نتايج اين آزمايش نشان داد كه استفاده متيونين كياهى تا داهي

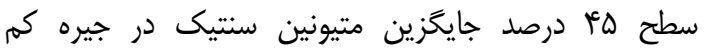

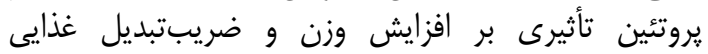
جوجههاى گوشتى نداشت، اما جايخزينى متيونين كياهى تأنى

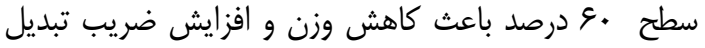

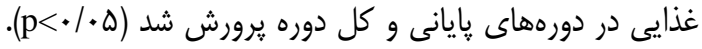

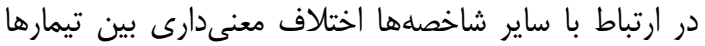

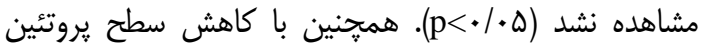

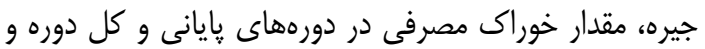

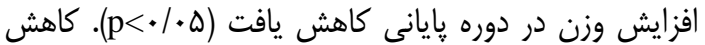

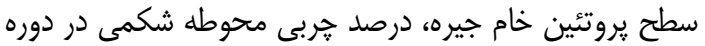

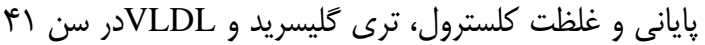

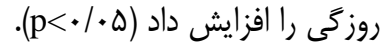

منابع

1. Banday, T., I.A. Baba, A.A. Khan, M. Untoo and F. Ganie. 2014. A study on the efficacy of herbal methionine (Nutri-methionine) supplementation with synthetic DL-methionine on the growth performance of broiler chicken. Poultry Science, 71: 325-330.

2. Benvenga, N.I. 1974. Toxicities of methionine and other amino acids. Journal of Agricultural and Food Chemistry, 22: 2-9.

3. Blair, R., J. Jacob, S. Ibrahim and P. Wang. 1999. A quantitative assessment of reduce protein diets and supplements to improve nitrogen utilization. The Journal of Applied Poultry Research, 8: 25-47.

4. Bregendal, K., J.L. Sell and D.R. Zimmerman. 2002. Effect of low- protein diets on growth performance and body composition of broiler chicks. Poultry science, 81: 1156-1167. 
5. Brosnan, J.T. and M.E. Brosnan. 2006. The sulfur containing amino acids: an overview. Journal Nutrition, 136: $16365-16405$.

6. Bunchasak, C., T. Sooksridang and R. Chaiyapit. 2006. Effect of adding methionine hydroxy analogue as methionine source at the commercial requirement recommendation on production performance and evidence of ascites syndrome of male broiler chicks fed corn-soybean based. International Journal of Poultry Science, 5: 744-752.

7. Chattopadhay, K., M.K. Mondal and B. Roy. 2006. Comparative efficacy of DL-methionine and herbal methionine on performance of broiler chicken. International Journal of Poultry Science, 5(11): 1034-1039.

8. Danesh Mesgaran, M. 1990. Amino acid in animal nutrition. First edition, Ferdowsi university press, 444 pp (Translated).

9. Drew, M.D., D.D. Maenz and A.G. Van Kessel. 2005. Interactions between intestinal bacteria and amino acid nutrition in broiler chickens. Degussa FA Amino News, 6(3): 19-28.

10. Duncan, D.B. 1995. Multipel range and multiple F tests. Biometrics, 11: 1-42.

11. Fancher, B.I. and O.S. Jensen. 1989. Dietary protein level and essential amino acid content: Influence upon female broiler performance during the grower period, Poultry Science, 68: 897-908.

12. Ferguson, N., S. Gates, J.L. Taraba, A.H. Cantor, A.J. Pescatore, M.L. Straw, M.J. Ford and D.J. Burnham. 1998. The effect of dietary ctude protein and phosphorus on ammonia concentration and litter composition in broilers. Poultry science, 77: 1085-1093.

13. Friedwald, W.T., R.I. Levy and D.S. Friedwald. 1972. Estimation of the concentration of low density lipoprotein cholesterol in plasma without use of the preparative ultracentrifuge. Clinical Chemistry, 18: 499-502.

14. Ghyasi, M.A. 2002. Application of soy protein concentrate in poultry pre starter feed. Scientific and Technical Journal. Aria Kian chick co. (Translated).

15. Hadinia, Sh., H. Moravej, M. Shivazad and M.M. Nabi. 2013. Bioefficacy comparison of herbal methionine versus synthetic methionine on growth performance basis in broiler chickens. Animal Production Research, 2(1): 15-27.

16. Jacob, G.P., R. Blair, D.C. Bennett, T.R. Scott and R.C. Newberry. 1994. The effect of dietary protein and amino acid levels during the grower phases on nitrogen excretion of broiler chicken. Page 309 in: Proceeding of Canadian Animal science Meeting of Saskatchewan, Saskatoon, SK, Canada.

17. Kamran, Z., M. Sarwar, M. Nisa, M. Nadeem, S. Mahmood, S. Amjid, R.H. Pasha and M. Nazir. 2011. Effect of low crude protein diets with constant metabolizable energy on performance of broiler chickens from one to thirty-five days of age. Indiam Journal of Animal Science, 81(11): 1165-1172.

18. Khan, S.A., N. Ujjan, G. Ahmed, M.I. Rind, S.A. Fazlani, S. Faraz, S. Ahmed and M. Asif. 2011. Effect of low protein diet supplemented with or without amino acids on the production of broiler. African Journal of Biotechnology, 10: 10058-10065.

19. Kidd, M.T., B.J. Kerr, J. Allard, S. Rao and J. Halley. 2000. Limiting amino acid response in commercial broilers. The Journal of Applied Poultry Research, 9(2): 223-233.

20. Kita, K., S. Matsunami and J. O;umura. 1996. Relationship of protein synthesis to mRNA levels in the muscle of chicks under various nutritional conditions. Journal of Nutrition, 126: 1827-1832.

21. Lepage, K.T., S.E. Bloom and R.L. Taylor JR. 1996. Antibody response to sheep red blood cells in a major histocompatibility (B) complex aneuploidy line of chickens. Poultry Science, 75: 346-350.

22. Meister, A. 1965. Intermediary metabolism of the amino acids. Biochem. Amino. Acids, 785. Academic Press, New York, Londan.

23. Namroud, N., M. Shivazad and M. Zaghari. 2008. Effects of fortifying low crude protein diet with crystalline amino acids on performance, blood ammonia level, and excreta characteristics of broiler chicks. Poultry Science, 87: 2250- 2258.

24. Offer, G. and P. Knight. 1984. The structural basis of water holding in meat. In: Development in Meat Science.

25. Rahimi, S.H. and A. Khaksefidi. 2006. A comparison between the effect of aprobiotin and antibiotic on the performance of broiler chickens under heat stress condition. Iranian Journal Veterinary Research, 7(3): 2328.

26. Rezaei, M., H. Nassiri Moghadam, J. Pourreza and H. Kermanshahi. 2006. Effects of dietary crude protein and supplemental lysine on broiler chickens performance, carcass characteristics and $\mathrm{N}$ excretion. Journal of Science and Technology of Agriculture and Natural Resources, 4(9): 171-179.

27. Safamehr, A., S. Yaghobzadeh and A. Nobakht. 2012. Effect of different levels of protein and probiotics on performance and immune response of broiler chicks exposed to heat stress. Iranian Journal of Animal Science, 42(2): 95-106.

28. Swain, B.K. and T.S. Johri. 2000. Effects of supplemental methionine, choline and their combinations on the performance and immune response of broilers. British Poultry Science, 41: 83-88.

29. Taska, I. and M. Kushima. 1979. Heat production when single nutrient given to fasten cockerels. Studies in the Agricultural and Food Science, 253-256.

30. Fige, R., P. Soucaile and G. Bestel-corre. 2010. Producing methionine without n-acetyle-methionine. United States Patent, No.0047879 AI.

31. Halder, G. and B. Roy. 2007. Effect of herbal or synthetic methionine on performance cost benefit ratio, meat and feather quality of broiler chicken. International Journal of Poultry Science. 12: 987-996.

32. Huynh, V. and R.C. Chubb. 1987. The induction of delayed type hypersensivity to dinitrocholorobenzene in the chicken. Avian Pathology, 16: 383-393.

33. NRC. 1994. Nutrient requirements of poultry. National Academy Press, Washington, DC.

34. Pinchaso, Y., C. Mendonca and L. Jensen. 1990. Broiler chick response to low protein diets supplemented with synthetic amino acids. Poultry Science, 69: 1950-1955.

35. SAS. 2002. SAS/STAT Users Guide. (Release 9.1) SAS Inst., Cary, NC. 


\title{
Effect of Herbal Methionine in Low Protein Diet on Performance, Carcass Characteristics, Immune Response and Some Blood Parameters in Broiler Chickens
}

\author{
Farzad Mohsenzadeh Tori ${ }^{1}$, Mansour Rezaei ${ }^{2}$ and Mohammad Kazemi Fard ${ }^{3}$
}

1 and 3- Graduated M.Sc. Student and Assistant Professor, Department of Animal Science, College of Animal Science and Fisheries, Sari Agricultural Sciences and Natural Resources University

2- Professor, Department of Animal Science, College of Animal Science and Fisheries, Sari Agricultural Sciences and Natural Resources University (Corresponding author:mrezaei2000@ yahoo.com)

Received: December 11, 2016 Accepted: February 6, 2018

\begin{abstract}
This study was conducted to evaluate the effect of different levels of herbal methionine in low protein diet on performance, carcass characteristics, immune response and some blood parameters in broiler chickens. In this experiment 240 day-old Ross 308 mixed broiler chicks were randomly divided into 6 groups with 4 replicates and 10 birds each in a completely randomized design. Treatments included: standard commercial diet with $100 \%$ synthetic methionine (DL-methionine) and low protein diet with different levels of herbal methionine (0, $15,30,45$ and 60 percent) replaced with synthetic methionine respectively in grower (11 to 24 days of age) and finisher periods (25 to 41 days of age).Decreasing protein level significantly reduced feed intake in finisher and whole periods and reduced body weight gain in finisher period of the experiment $(\mathrm{p}<0.05)$. With increasing herbal methionine levels up to $60 \%$ in low protein diet, feed conversion ratio significantly increased and body weight gain decreased in finisher and whole periods of the experiment $(p<0.05)$. Decreasing dietary protein level, increased abdominal fat percentage and blood TG, cholesterol and VLDL concentrations at 41 days of age. Results of the present study indicated that herbal methionine could be replaced instead of synthetic methionine in low protein diet in grower and finisher diets of broiler chicks without any adverse effect on feed conversion ratio.
\end{abstract}

Keywords: Broiler Chicks, Herbal Methionine, Low Protein Diet, Performance 